\title{
Aproximación a la empresa artesano-mercantil francesa en la segunda mitad del siglo XVII. Los mercaderes-fabricantes de peines de Madrid (1659-1679)
}

\author{
Maria Dolores Ramos Medina*
}

«Solo el Peynero es quien gasta jatancia, que por los peynes llevan oro a Francia; pero el Francés no me espanto que reyne, porque bien sabe las puas de un peyne". Sátira general y burlesca y entretenida que trata de la quexa que tienen las artes y oficios de Madrid...

\section{INTRODUCCIÓN}

El crecimiento urbano de Madrid en el siglo XVII estuvo acompañado de un desarrollo importante de sus gremios ${ }^{2}$. En esta coyuntura, sin embargo, la capital del reino, centro suntuario de primer orden en el mercado peninsular, no supo canalizar los esfuerzos gubernamentales para ocupar un lugar destacado como núcleo productor, ya que la principal preocupación de los banqueros madrileños no era precisamente la de responder a las necesidades de una industria en busca de capital. En efecto, no hubo espacio para la inversión capitalista en la industria madrileña, pues la importancia financiera de la ciudad nacia del papel político que desempeña-

* Becaria UNED

Sanche $\angle$ Alonso. Cristina, Contribución a la bibliogratia de impresos espanoles de temática madrileña (1450-1700). Tesis doctoral, Servicio de publicaciones, Universidad Complutense. Madrid, 1982, vol. II, pág. 324.

Moral Roncal. A.M. "Los gremios menores madrileños: Papel de la Real Sociedad Económica Matritense en la formación de sus ordenanzas". Torre de los Lujanes. Madrid. 3.

Trimestre, (1992), pág. 86 
ba como capital del Imperio y Corte de los Austrias ${ }^{3}$, dirigiendo las inversiones de los hombres de negocios hacia la comercialización de productos, fundamentalmente extranjeros o procedentes del hinterland regional madrileño, que la clientela de la Corte demandaba, como paso previo, en algunos casos, a su participación en las redes financieras de la Corona. Los mercaderes fabricantes peineros encontraron en este ambiente una demanda cada vez más especializada y elitista ${ }^{4}$ que les separaba día a día de la producción local, acercándoles aún más a los mercados productores europeos de donde se abastecían ${ }^{5}$.

Sabemos que el arte de fabricar peines, introducido en Madrid aproximadamente en 1643 por un grupo de maestros de origen francés, entre los que se encontraban Domingo Vallejo y Bernardo Peberán, tenía su centro de operaciones en dos focos mercantiles de primer orden en la parroquia de Santa Cruz: la Puerta del Sol y sus inmediaciones ${ }^{6}$, y en menor medida la calle de Toledo, donde encontramos la tienda de Pedro de la Peña ${ }^{?}$.

Los precios y salarios en constante crecimiento, ofreciendo grandes posibilidades de empleo para mancebos y oficiales, asi como la cobertura favorable al establecimiento de las empresas de los maestros peineros ${ }^{8}$, unido a la fragilidad entre población-recursos en el país vecino ${ }^{9}$, son razo-

ZYLBEREERG, M., «Un centre financier 'periphérique': Madrid dans la seconde moitie du xVIIIe siecle", Revue Historique, 546 (1983). págs. 267-269. Para D. Ringrose Madrid no acertó a ser la base de una posible protoindustrialización ("El legado de Madrid", Revista de Occidente, Extraordinario VII, $n^{\circ} 27-28$, (1983), págs. 69-70), cosa bien diferente de lo que sucedió en Córdoba como ha estudiado J.I. ForTEA PEREZ, Córdoba en el siglo XVI: bases demográficas y economicas de una expansión urbana. Córdoba, 1981, pág. 38.

FAYARo, J. y LaRquIE, C., "Hôtels Madrilenes et démographie urbaine au XVIle siècle", Mélanges de la Casa Velazquez, IV, 1968, pág. 239

Ringhose, D. Madrid y la economía española. 1560-1850. Madrid, 1985. pág. 334

- Archivo Villa de Madrid (en adelante AVM), Secretaría, 2-245-3. La elección de dos veedores y examinadores por el gremio de peineros en el siglo XVIII ( 27 de enero de 1702, 20 de febrero de 1727, 22 de noviembre de 1728 y 24 de julio de 1747) confirma que su centro de actuación continúa siendo la Puerta del Sol, centro neurálgico de la city madrileña, y la calle de Toledo, donde se localizan sus establecimientos comerciales y financieros. Ver ZYLBERBERG, M., op. cit., pág. 271: LOPEZ CASTAN, A., "Los gremios de la Puerta del Sol y su contorno en el siglo Xvili", Establecimientos tradicionales madrileños, Cuaderno IV. Madrid 1984, págs. 87 y 88; GIMENO PAScual. A. M. "Puerta del Sol y su circulo colindante", Establecimientos tradicionales..., pág. 100. Estos dos últimos autores coinciden en señalar que esta zona es ocupada por establecimientos correspondientes a gremios menores. Para un estudio de la zona en el siglo XVI: ALVAR ESOUERARA, A. Estructuras socioeconómicas de Madrid y su entorno en la segunda mitad del siglo xv. Madrid, Universidad Complutense, 1988, pág. 859.

Archivo Histórico de Protocolos de Madrid (en adelante AHPM), Prot. 7251, fol. 112.

* AlCouffE, D. "Contribution à la connaissance des émigrés français de Madrid au XVIle siècle". Melanges de la Casa Velázquez, II, (1966), pảg. 183.

LANGE. Ch. La emigración francesa en Aragon. Zaragoza, 1993. pág. 72. 
nes suficientes para el traslado a la Península de un número creciente de maestros y oficiales franceses integrantes de este oficio. Algunos de ellos se instalan, en un primer momento, en los obradores de las ciudades cercanas a la frontera (Zaragoza, Huesca, Calatayud, Barbastro, Pamplona o Barcelona), procedentes de Languedoc ${ }^{10}$ y Béarn ${ }^{11}$, principalmente. El análisis de las fuentes notariales nos descubre "grosso modo" el grado de participación de estos agremiados en la economía madrileña, ya que atraídos por las posibilidades de enriquecimiento que les ofrece la Corte pronto trasladan sus casas y negocios a Madrid, entrando a formar parte de esa élite burguesa que constituyen los maestros-empresarios, equivalentes al maitre-marchand, artesanos con intereses comerciales y financieros que, introducidos en negocios propios de los gremios del comercio, bien en tienda o como mercaderes mayoristas, se convierten en un elemento vertebrador de esta comunidad artesanal en el Madrid de finales del siglo XVII.

Como súbditos del rey Cristianisimo, adscritos a la cofradía y hospital de San Luis, sufrieron las sucesivas represalias y embargos de sus bienes y mercancias que con cartesiana precisión se repitieron durante este período de especial conflictividad en Europa. Tenemos noticias de que a Domingo Vallejo le sería retirado en 1668 el título de peinero real ${ }^{12}$. Del mismo modo, Bernardo Peberán, maestro peinero francés residente desde hacia más de treinta años en la Península, casado con una española y con fuertes intereses económicos tanto en Madrid como en Zaragoza, estaría sujeto en 1677 al pago de la "farda", impuesto sobre los franceses en período de conflicto bélico con Francia ${ }^{13}$.

La permanencia en suelo español les fue incorporando activamente a la sociedad madrileña, llegando alguno de ellos a incardinarse en las redes de

\footnotetext{
Las casas de Juan Tisne, Juan Arçisete, Juan Cordurie y Diego y Jacques Pineo proceden de Languedoc. Ver árboles genealogicos.

OzanaM, D., "Les français à Madrid dans la deuxieme moitie du XVIlle siècle", en Madrid en la época moderna: Espacio. sociedad y cultura. Madrid 1991, (2." ed.), pág. 181: Anson Calvo. C.: Demogratia y sociedad urbana en la Zaragoza del siglo xvi. Zaragoza. 1977, págs. 192 y 193 (tablas 74 y 75: "Emigrantes a la parroquia de San Pablo procedentes de Bearne", confirma la información procedente de protocolos madrileños).

Archivo General de Palacio (en adelante AGP), Expedientes Personales. Caja ( $C^{a}$ ) 1065-18. "Domingo Vallejo, peinero real". También sabemos que Diego Pineo y Pascual del Campo fueron represaliados por contravenir el bando que ordenaba la salida de la Corte de todos los franceses (Archivo Histórico Nacional AHN). Consejos. Libro 2786, fols. 361 y 356, respectivamente. Otro caso es el de Bernardo de la Peña, también peinero real, que fue objeto de embargo y desembargo de sus bienes. Archivo General de Simancas (AGS), Contaduria del Sueldo, $2^{\mathrm{a}}$ Serie, leg. 150. "Bernardo de la Peña, peinero de S. M. 20 de diciembre de 1673,"

Bravo Lozano. J., "La emigración a Madrid", en Madrid en la época moderna: espacio, socledad y cultura. pág. 143
} 
clientelaje regio y obtener el título de «peinero real». Esta situación les proporcionaba, en calidad de criados de Su Majestad, privilegios y exenciones fiscales, beneficios que repercutian favorablemente en el desarrollo de la actividad comercial, aparte de que disfrutaban del derecho a médico y botica ${ }^{14}$.

La participación de los maestros peineros en la naciente economia capitalista madrileña es el marco donde se inserta el presente artículo ${ }^{15}$. A partir de aquí el análisis microeconómico esbozado nos proporciona una aproximación a las formas de organización y actuación de esta peculiar empresa en Madrid desde 1659, fecha clave en las relaciones comerciales entre Francia y España. Asimismo, diseñaremos las estrategias de los escritorios de comercio de este colectivo empresarial dentro del mundo gremial madrileño, avanzando una somera geografía de sus mercados nacionales y europeos. De esta forma, en sólo unas páginas, pretendemos emprender el difícil camino de poner luz en la "tenebrosa oscuridad" que ha caracterizado el análisis microeconómico de la empresa extranjera en el ámbito gremial madrileño del siglo XVII.

Analizada una treintena de maestros-mercaderes en Madrid entre los años 1659 y 1679 en el marco de la alianza entre el capital y la habilidad técnica, la evolución seguida por los «peineros» con casa abierta en la villa avanza por estadios muy precisos ${ }^{16}$. En primer lugar, aparece el modesto artesano que comercializa la producción de su taller-tienda, grupo al que pertenecen también, en una primera fase, algunos de los maestros peineros

Capella Martinez, M., La industria de Madrid. Madrid, 1962, vol. I, pág. 468.

La aportación de Pierre Vilar en La Catalogne dans L'Espagne moderne. Barcelona, 1968 vol. III, págs 156-163, tuvo su continuidad en MARtinez SHAw, C. Cataluña en la carrera de Indias. Barcelona, 1981, págs. 43-45, quien localiza a un grupo de agremiados que participan en la Cárrera de indias. El profesor Pere Molas RiBalta analiza el fenomeno desde un punto de vista social en su libro Los gremios barceloneses del siglo xvml. Madrid, 1970, pág. 28, al igual que Fortea PEREZ, J.1., op. cit. Para el caso aragonés, ver Gomez Zorraouino, J.I. La burguesía mercantil en el Aragón de los siglos xvi y xvil (1516-1652). Zaragoza, 1987, y para el castellano es fundamental el libro de GonzalEz EnCISO, A., Estado e industrialización en el siglo xvili. La fábrica de Guadalajara. Madrid, 1980, pág. 722, entre otras publicaciones suyas. La situación valenciana ha sido abordada por Franch, R. en Crecimiento comercial y enriquecimiento burgués en la Valencia del siglo xwm. Valencia, 1986, pág. 297, asi como en su obra más reciente El capital comercial valenciano en el siglo xvil. Valencia, 1989, págs. 48-49. Por último, los artículos de Al CALA-ZAMofaA y QUEIPO DE LLANO, J., "Organización laboral, sueldos y salarios en una fábrica santanderina, a finales del Antiguo Régimen: La Cavada, 1750-1820". Estudios, Zaragoza, 1973, págs. 73-92, y "La fabrica de hierro colado de Corduente, en Molina de Aragón (1642-1672). Estudios. Zaragoza, 1974, págs. 611-19, nos sugieren la conveniencia de canalizar algunas de las nuevas vocaciones del historiador hacia el analisis de la unidad industrial desde las grandes empresas mineras o los astilleros hasta las de indole artesanal a través del análisis de fondos documentales en archivos provinciales y privados.

"MARTINEz Shaw, C., op. cit., pág. 44 
de origen francés avecindados en ciudades como Zaragoza o Huesca y que en calidad de asalariados del capitalista peinero madrileño participan en el abastecimiento de mercancías a la Corte. En segundo lugar, encontramos al grupo de peineros capitalistas que forman compañias con otros maestros mercaderes y que adquieren a maestros asalariados - con frecuencia instalados fuera de Madrid - una producción adicional que comercializan en las tiendas de la Corte. A este grupo se unen algunos de los maestros asalariados procedentes de Zaragoza o Huesca que, tras acceder a la oficialia durante dos años, se incorporan activamente al grupo de maestros capitalistas ${ }^{17}$. Finalmente, como élite artesanal que mantiene su etiqueta gremial, pero que se ha pasado al ejercicio del gran comercio, figura un grupo reducido de "mercaderes de lonja peineros", de quienes nos ocuparemos en otra ocasión a fin de no extendernos demasiado en el presente trabajo.

Observamos, pues, que el fabricante de este escritorio, actuando de enlace entre la economía gremial y la capitalista, no sólo aúna dos conceptos, comercio y artesanía - términos socialmente excluyentes ${ }^{18}$-, sino que también participa en las actividades típicas de la burguesía mercantil madrileña ${ }^{19}$, invirtiendo el capital acumulado de la comercialización en una amplia gama de productos, asociado en compañías con otros maestros-mercaderes peineros, asi como con mercaderes merceros, joyeros o especieros con tienda abierta ${ }^{20}$ en Madrid para más tarde convertirse en un verdadero hombre de negocios e introducirse en las redes del gran comercio madrileño con Europa y América, adquiriendo los medios necesarios que le permitan mejorar su posición social. De este modo, el comercio en "lonja" o al por mayor y el comercio en tienda o "vareado" conviven en armonía.

\section{ORGANIZACIÓN DE LA EMPRESA ARTESANO-MERCANTIL PEINERA}

La empresa peinera, como taller artesanal, se desarrolla y evoluciona en el marco de las rígidas normativas del gremio de la Especieria de la calle

Caso análogo es el de Nicolás del Frago, de origen aragonés, que se traslada a Barcelona en busca de nuevas oportunidades. Ver PEREz SARRion, G., "Compañias mercantiles rurales y urbanas de Cataluña en el interior peninsular durante el siglo xvill", en El comercio en el Antiguo Régimen. II Reunión Científica. A.E.H.M. Las Palmas de Gran Canaria, 1994, pág. 239.

: Molas Ribalta, P., La burguesia mercantil en la España del Antiguo Régimen. Madrid. 1985, pág. 18

14 Gomez Zorraduino, J.I., op. cit, págs. 56-117

*) AHPM, Prot 7250 , fols. 12-12v. "Escritura de Constitución de compañía el 14 de enero de 1662 ”. 
de las Postas y Portal de Santa Cruz, al que se encuentran adscritos los maestros peineros. Éstos, sin gremio propio durante el siglo diecisiete ${ }^{21} \mathrm{y}$, por tanto, sin una corporación coordinadora de su actividad en Madrid, se sentían desprotegidos. No sucedia lo mismo en ciudades como Barcelona, donde existía un gremio de peineros ya en esta época. Esta situación provocaba serios problemas para el desarrollo de la profesión - a pesar de resultar favorable para el maestro capitalista-, ya que, según quejas de los propios maestros artesanos, la inexistencia de un gremio propio ocasionaba un vacío legal en materias como la formación de personal especializado en la fabricación de peines, el control de calidad y de la cantidad del producto, la supervisión de la venta, y todo un sinfín de matices que, al no estar regulados por unas ordenanzas, se establecian en claúsulas de contratos privados entre maestros y oficiales o entre maestros y capitalistas, en el caso del contrato de "encargo". Esta situación, además, perjudicaba a la Corona, pues mientras los peineros estuviesen agrupados en el gremio de la Especiería, los beneficios fiscales que se derivaban de su actividad eran muy inferiores a los que se hubieran recaudado de estar agrupados en un gremio independiente.

Sin embargo, no será hasta comienzos del siglo xVIII cuando el Estado se apresure a reglamentar minuciosamente todo lo relativo a la vida económica madrileña - a pesar de las numerosas ordenanzas gremiales aprobadas a lo largo de las dos centurias anteriores-, obteniendo entonces los peineros la facultad de instituirse en gremio y de disponer de unas ordenanzas. Así, el 20 de febrero de 1727 el escribano mayor de cuentas de la villa de Madrid da fe de que el gremio de peineros se reunió para la elección de dos examinadores y veedores por orden del corregidor y superintendente de las Rentas Reales de la Villa, como "previenen las ordenanzas aprobadas por el Consejo real», lo cual viene a confirmar que la existencia de constitución del gremio de peine-

AVM, Secretaria, 2-245-3, "Diego Rodriguez Mendo de Valderas en nombre del gremio de la especieria de la calle de las Postas y Portales de Santa Cruz", 15 de junio de 1669. Los peines y estuches para el pelo eran incluidos como mercancías misceláneas en los aranceles del gremio de la especiería: Alvar Esquerra, A. Estructuras socioeconómicas de Madrid..., págs. 846-48. Por otro lado. LOPEz CASTAN, A., Los gremios artisticos madrileños..., págs. 115-118, recoge noticias del gremio de peineros en 1622, sin embargo nuestra noticias no corroboran esta fecha sino que bien al contrario deja claramente confirmada su incorporación en el gremio de la Especiería, al menos, hasta finales del siglo XVI: AVM. Secretaria, 2-244-12 y 2-244-11, 5 de agosto de 1722, fol. 6v. Ver también PASTOR MAteos, E., La evolución gremial de Madrid (tesis doctoral inédita), Universidad Complutense de Madrid, vol Ii. Apéndice documental: "Ordenanzas para el régimen y gobierno de los individuos del gremio de peineros de esta Corte aprobadas por el Real y Supremo Consejo de Castilla. Madrid, 1801. 
ros es una realidad por esta fecha y que dispone de unas ordenanzas que regulan su actividad muy anteriores a las de 1769, a las promulgadas por real carta el 5 de abril de 1794 a petición del Consejo, el cual habia instruido expediente el 9 de mayo de 1783, ni siquiera las anteriores que datan de 1769 , o a las más conocidas publicadas el 21 de marzo de $1801^{22}$.

En segundo lugar, el municipio siempre tuvo una relación directa con la empresa gremial ${ }^{23}$, no sólo en el ámbito de la producción sino también en el de la distribución, siendo condición sine qua non la concesión de licencias para la comercialización de los productos. En 1676 Bernardo del Campo, maestro peinero, pretendía obtener licencia para poder vender peines por las calles, impidiéndoselo los mercaderes de la calle Mayor con el pretexto de que comercializaba también mercancias prohibidas ${ }^{24}$.

2? Larruga y Boneta, E. de, Memorias politicas y económicas sobre los frutos, fábricas y minas de España. Madrid, 1794, 26 vols, Tomo IV, Memoria XXIV: “Peineros", págs. 221-222. Según este autor el gremio se regía por ordenanzas aprobadas por la Junta General de Comercio en el año 1762 aunque con algunas restricciones impuestas por el Consejo por vía de suplemento.

23 ARCO, R. del, Apuntes sobre el antiguo régimen municipal de Huesca. Huesca, 1910, págs. 107 y SS. MAiso GonzALEZ, J., “Disputas entre Felipe IV y Zaragoza en 1653», Estudios, Dpto. de Historia Moderna, Facultad de Filosofía y Letras, Zaragoza (1974), pág. 41. Con la instalación de la Corte en Madrid se produjo un cierto cambio pues la supervisión de la actividad gremial (juramento de veedores, visitas, fijación de precios, revisión de pesos y medidas, etc.) pasó a manos de la Sala de Alcaldes de Casa y Corte, siendo las únicas relaciones mantenidas por los regidores con los gremios las que se refieren a cuestiones fiscales, esto es, recaudación de alcabalas y cientos, sobre todo: Ver Hernandez, Mauro, A la sombra de la Corona: Poder local y oligarquia urbana (Madrid, 1606-1808). Madrid, 1995, págs. 35-41 y DE LA GuARDIA, M.C., "La Sala de Alcaldes de Casa y Corte. Un estudio social", Irvestigaciones Históricas Época moderna y contemporánea, 14 (1994), pág. 55. No obstante, el concejo madrileño mantendria competencias compartidas por la Sala e incluso este último organismo se veria con frecuencia envuelto en conflictos de compotencias con otras instituciones, no sólo municipales sino también nacionales: AHN, Consejos, leg. 7181/100, "Consulta al presidente del Consejo, 10 de septiembre de 1671 ".

24 AVM, Secretaria, 1-466-1, Año 1676. "Informe sobre Bernardo del Campo, maestro peinero que pretende se le dé licencia para poder vender peines por las calles" y 2-159-119, “Provisión de 26 de mayo de 1674 que prohibe vender por las calles". También aquí logró el Concejo madrileño defender sus competencias frente a las aspiraciones de la Sala de Alcaldes, institución con competencias en materia económica en la jurisdicción madrileña. Ver, al respecto: Novisima recopilación de las leyes de España mandadas formar por el señor don Carlos IV. Madrid. Tomo II, Libro III. Titulo XX: "De las rondas y visitas de la Corte, por los alcaldes de ella y sus ministros" en la ley II: "Modo de proceder los alcaldes de la Corte en las rondas y visitas que deben hacer en ellas (por pragmática de 12 de diciemhre de 1583 ), pág. 170, donde se estipulaba la visita a tiendas, posadas y mesones donde se acoge a gente forastera. Del mismo modo en el título XXVII, Ley II, pág. 310: “Asignación de quatro alcaldes de Corte para el conocimiento de las causas criminales y modo de proceder en ellas" se recogía que la Sala pueda hacer posturas de los mantenimientos de la Corte: Ver AHN, Alcaldes de Casa y Corte, leg. 49.814 (1621-1670), Informes de 12 de julio y 23 de agosto de 1668, donde se recoge un expediente del gremio de cereros pidiendo a la Sala postura en el precio de la cera y otras pretensiones. GOnZALEZ DE AMEZUA y MAYO, A.: "Las primeras ordenanzas municipales de la Villa y Corte de Madrid (1585)". Revista de la Biblioteca. 
La estricta concesión, incluso para la venta ambulante, tenía como objetivo último evitar la masiva afluencia de buhoneros en la Corte, permitir a las autoridades municipales vigilar a los vendedores callejeros, impedir la competencia desleal con los gremios eminentemente comerciales e incluso perseguir el fraude fiscal.

Por el fuerte carácter comercial que tenian los negocios de estos artesanos, estaban gravados con los impuestos propios de la comercialización, bien en el trato al por menor (alcabala y cuatro por ciento) ${ }^{25}$ bien en la venta al por mayor o en almacén (la alcabala del viento cobrada en las aduanas de la villa, en concepto de producto importado) ${ }^{26}$, aparte de que en tiempo de guerra debian hacer frente a ciertas imposiciones de carácter extraordinario, como la ufarda» ${ }^{27}$, impuesto que recaía sobre los escritorios de fabricantes de origen francés, cuando no se les confiscaban los géneros que despachaban por estar prohibido el comercio de manufacturas de Francia tras la ruptura de hostilidades, como sucedió en 1657 con la promulgación de una real orden fechada en 11 de septiembre dirigida contra el contrabando de mercancías procedentes de Francia, Inglaterra y Portugal, con quienes España estaba en guerra ${ }^{28}$, a pesar

Archivo y Museo del Ayuntamiento de Madrid, (1926), n 12, pág. 12.; SAnchez Gomez, R.I.. Estudio institucional de la Sala de Alcaldes de Casa y Corte durante el reinado de Carlos II. Madrid, 1989 págs. 45 y 86 . Recordemos, además que la administración del concejo madrileño se ocupaba de múltiples actividades, algunas de las cuales también eran competencias de la Sala de Alcaldes.

Hasta que por Real Cédula de Carlos III de 12 de febrero de 1788 se concedió a los gremios menores de la Corte exención tributaria. Ver LOPEZ CASTAN, A., Los gremios artísticos.... op cit., pág. 165 y nota 48 .

En 1669 contabilizaba nueve tiendas de peineros de las que siete se localizaban en la Puerta del Sol y las restantes en la calle Toledo, considerando a Bernardo Peberán, Pedro Mercadet y a Domingo Vallejo como los más importantes mercaderes peineros que pagaban a!calaba y el cuatro por ciento. Este dato entre otras connotaciones nos proporciona, a la luz de las fuentes notariales consultadas, el desconocimiento de la actividad económica real de estos artesanos, además de advertirnos de un flagrante fraude fiscal en el seno de la comunidad mercantil madrileña.

AHPM. Prot 7248 , fol. 128-128v, el 3 de abril de 1660. Poder notarial a Pedro Mercadet, maestro peinero, de Juan de la Plaza, maestro peinero que tuvo que abonar el derecho de la "farda" y ahora reclama cincuenta docenas de peines que dejó en concepto de prenda; AHN, Consejos, leg. 7119, exp. $n^{\circ} 16$ "don Diego Felipe de Ayerbe, arrendador del impuesto de franceses de esta Corte, 1658 y $\operatorname{Exp} . n$ 2 , donde se recoge el valor del importe del impuesto: los maestros de oficios mecánicos debian abonar dieciséis maravedies diariamente, los trabajadores ocho maravedies y el resto treinta y dos.

28 Biblioteca Nacional de Madrid (BNM), Varios Especiales. 196-104, "Nombramiento de veedor del contrabando en 1667" y AHN, Alcaldes de Casa y Corte, Libro 1259, "Pragmática que Su Majestad manda publicar sobre la reformación en el excesso de traxes, lacayos, y coches, y prohibición del consumo de mercanderias de Francia, y sus dominios, y otras cosas", fol. 70; SANCHEZ BELEN, J.A y RAMOS MEDINA, M.D., "Los comerciantes franceses en Castilla y la represalia de 1667". Espacio. Tiempo y Forma, IV, 7, (1994). Madrid, UNED, págs. 287-288 
de los numerosos permisos y licencias concedidas. Por lo mismo, estaban sujetos a las numerosas Pragmáticas publicadas contra el lujo ${ }^{29}$, lo que provocaba, como en el caso anterior, severos registros en los almacenes y talleres-tiendas de nuestros artesanos, aunque en la mayoría de los casos con poco éxito.

Desde el punto de vista organizativo, la empresa peinera estaba dirigida por el propio artesano que era el encargado de gestionar los asuntos de la misma a través del "escritorio de fabricante» como unidad básica de producción y distribución ${ }^{30}$. La organización de la mayoría de estos negocios requería de un administrador (cuadro l) que, ajustado a la estructura gremial de la época, se encargara de la gestión y organización del negocio. Como representante de los intereses de la empresa firmaba contratos de arrendamientos, escrituras de "asiento" con mancebos, oficiales y vendedores, a la vez que otorgaba poderes a corresponsales en otras ciudades donde la compañía tenía intereses económicos.

Como empresa dedicada a la producción y distribución, requiere de un plan contable ${ }^{31}$ que disponga de un libro de "caxa» y otro llamado "manual», así como de un libro donde copiar la correspondencia recibida ${ }^{32}$. En la compañía formada por Bernardo Catalinat, mercader peinero, y Juan Cantón, mercader de mercería, cada uno de los socios «debe tener su libro de cuenta y razón» ${ }^{3: 3}$. Desde antiguo se obligaba a los comerciantes

AHN. Consejos, leg. 7187. 4 de mayo de 1677, relativo a la salida de oro y plata y prohibición de telas de oro y otros géneros y leg. 7139. "Real pragmática original de 11 de septiembre de 1657 de prohibición de comercio, con Francia. Portugal e Inglaterra y de trajes y vestidos". Loh'? CASTAN, A., op. cit.. págs. 584-589 confirma la repercusión que tuvieron estas pragmáticas sobre la producción de diferentes industrias madrileñas.

Siguiendo el esquema utilizado por el profesor Joan Carles MAlXE. AL TLS. Comercio y Banca en la Cataluna del siglo xvit. Barcelona. 1994, págs. 37-113. introducimos el termino "escritorio de fabricante" ya utilizado por la historiografia en otros ámbitos geográficos peninsulares.

SolohzANo. B. Salvador de. Libro de Caxa y Manual de cuentas de mercaderes y otras personas. con la declaracion de ellos. Madrid. 1590: Novisima Recopilacion de las Leyes de Esparia. Madrid. 1805. Libro IX. Titulo Primero, Ley XII; LE.MARChANL, Y.. "Style mercantile et comptabilité. Annales.E.S.C. 1995, 1, págs. 161-63.

Picarido y Gomez. A. (ed.). Memorias de Raimundo de Lantery, mercader de Indias en Cádiz. 1673-1700. Cádiz. 1949. págs. 53 y 79-80.

AHPM. Prot 7250 . fols. 12-12v, donde se indica que en el tambien denominado libro de "Caxa" se tomaria nota "de lo que se debiere a la dicha compania y lo que la dicha compañia debiere prorrata y la perdida y ganancia que de ella resultare ha de ser por mitad". según el capital aportado por cada socio. del gasto que cada uno hiciese para que no falte la cuenta y razón: AHPM, frot 7250, fols 183-185v: "Constitución de compañia Corral Tisne el 17 de mayo de 1662": AHPM. Prot. 7248, fols. 314-317v, "Constitución de Compania Corral-Davadia, 11 de diciembre de 1659 ". En estos documentos se estipula además que cada cierto tiempo se tendrá que hacer "avanço". o lo que es lo mismo, balance de las pérdidas y ganancias de la compañia. Ver también Solorzano, B. Salvador de, op. cit., pág. 23 
a llevar su contabilidad "por debe y ha de haber» para que «con ello puedan dar cuenta de cómo y en qué han pagado las mercancias que trajeron de reinos extraños, sin que entre la hoja del debe y el haber haya hojas en blanco", y todo ello en castellano, además de exigírseles la utilización de papel sellado ${ }^{34}$, requisitos que no siempre cumplían.

Debido a la acumulación de capital comercial, la movilidad de algunos de los miembros del gremio de peineros y su espiritu de empresa condujeron la transformación de la casa-taller en Ionja. Esta unidad de almacenamiento al por mayor estaba dirigida por una élite mercantil de claro origen gremial ${ }^{35}$.

\section{CUADRO $\mathbf{I}^{36}$}

\begin{tabular}{|ccccc|}
\hline \multicolumn{4}{|c}{ ADMINISTRADORES DE LAS CASAS TIENDAS DE PEINEROS EN MADRID } \\
\hline Administrador & Vecindad & Protesión & Casa tienda (1) & Localidad \\
\hline Tristán de Cali & Madrid & Maestro-peinero & Bartolomé Davadía & Madrid \\
Juan de Tapia & Zaragoza & Maestro-peinero & Juan Cordurie & Zaragoza \\
Esteban Durenca & Madrid & Maestro-peinero & Juan Cordurie & Madrid \\
Pedro de Iriarte & Madrid & Mercader (2) & Pascual del Campo & Madrid \\
Juan Cantón & Madrid & Maestro-peinero & Pedro Mercadet & Madrid \\
Juan Lagiera & Madrid & Maestro-peinero & Pedro Mercadet & Madrid \\
Juan Turena & Madrid & Maestro-peinero & Pedro Mercadet (3) & Madrid \\
Guillermo Plugat y & & & & \\
Juan Berber & Madrid & Mancebos de tienda & Bernardo Peberán & Madrid \\
\hline
\end{tabular}

(1) Maestros mercaderes propietarios del negocio.

(2) En 1672 Pascual del Campo, mercader de lonja y peinero en la Corte, otorga un upoder especial a Pedro de Iriarte, mercader de Madrid, en calidad de representante-cobrador de su casa comercial en esta localidad para el cobro y recibo de cantidades otorgando carta de pago. Además de cobro de débitos, ajuste de cuentas, esperas y poderes para otorgar cualquier instrumento comercial, esto es, papeles sujetos, préstamos-obligáión. letras de cambio, etc.

(3) Juan Cantón, maestro peinero, desempeña ese cargo hasta 1672, cuando es sustituido por Juan Laglera hasta el año 1683, cuando la tienda de Pedro Mercadet y Bernardo Mercadet, su padre, pasará a ser administrada por Juan de Turena, con plenos poderes en la administración y gestión de la casa-tienda sita en la Puerta del Sol de Madrid.

3. Rodriguez Villa, A., Curiosidades de la Historia de España. La Corte y la Monarquia de España en el año 1636 y 1637. Madrid, 1886, Tomo ll, págs. 231-232.

35 La comercialización en estas unidades de almacenamiento correspondia en los negocios de estos artesanos al sistema de "lonja abierta".

3*: Elaboración propia. Se trata de empresas con un claro carácter mercantil, constituidas en compañias comerciales donde uno de los socios, en la mayoría de los casos analizados, adquiere el "status" de administrador. 
La gestión contable de la empresa también corre a cargo del administrador, delegando en cajeros el cobro de las mercancías o haciéndolo él mismo. La amplitud de poderes recogidos en los documentos notariales nos permite apreciar la versatilidad y mimetismo que caracteriza a estas empresas ${ }^{37}$. Por otra parte, en su funcionamiento interno, el negocio de los peineros en Madrid tiene una doble vertiente: por un lado, la organización de la actividad fabril; por otro, la comercialización en el marco de una economía preindustrial dominada por las ordenanzas gremiales ${ }^{38}$. Esto último les permite introducirse en el gran comercio, así como en el negocio de la comisión y el préstamo bancario.

El obrador del escritorio de fabricante estaba compuesto por una plantiIla con un número limitado de oficiales y mancebos (cuadro II), fundamentalmente de origen francés, asi como de vendedores de peines en tienda y vendedores ambulantes (cuadro III), que a veces ejercian otras funciones ${ }^{39}$ como personal de confianza del maestro-mercader, representándole en cobros a clientes o en compras de mercancias a otros maestros peineros.

Las escrituras de "asiento" en casa de un artesano, además de estipular el salario ${ }^{40}$ y el periodo de desarrollo de la actividad laboral, recogían otros muchos aspectos: derecho a ropa limpia (un par de zapatos y una camisa), derecho a cama y comida, y a ser atendido en caso de enfermedad durante quince dias, siempre que no fuera contagiosa. Asimismo, se les abonaba el importe de la comida si se realizaba fuera de la casa-taller hasta dos reales y medio, estando siempre presente en estos documentos la exclusividad, bien para fabricar o vender la producción de su amo. También aparecia recogido en estos documentos la recuperación de días perdidos por el doble de la jornada laboral, esto es, trabajar dos jornadas por cada una de ausencia.

AHPM, Prot. 7249, fols. 333-334, "Carta de poder, para administrar negocios en la ciudad de Zaragoza", y Prot., 7252, fol. 607, "Disolución de Compañia de mercaderes peineros: Guillermo Cordurie y Andrés Manente, 1664".

"Especializados los maestros, unos en "madera de box", y otros en "madera del aire". Para los primeros el examen consistia en fabricar dos peines modelo "moyenes", dos casperas, dos peines con púas delgadas por ambas partes, vaciados y bien asolados. Para "madera del aire" un escarpador, la mitad posado, otro de alavé del $n^{\prime} 6$ y otro ensetado.

i4 Valladafes de Sotomayor, A., Semanario Erudito. Madrid, Vol. XXVI, pág. 162, recoge los pasos de un mancebo en las tiendas de los Cinco Gremios Mayores: challaremos, a más de la educación cristiana y timorata. el que diariamente va adquiriendo conocimientos utilisimos en el comercio". En la segunda mitad del siglo xvil, las fuentes notariales confirman este hecho llegando en algunos casos a ser incorporado a los negocios del taller como corresponsal de la empresa e incluso formando parte de compañias mercantiles.

41) Al formar parte de una inmigración estacional, muchos de estos mancebos y oficiales cobraban su salario en libras tornesas, moneda francesa, como Juan Dupón (AHPM, Prot. 7251, fols. $41-41 \mathrm{v})$. 


\section{CUADRO II}

\begin{tabular}{|lccc|}
\hline \multicolumn{4}{c|}{ NÓMINA DE OFICIALES PEINEROS (1659-1679)* } \\
\hline Periodo (años) & Salario & Fecha contrato $^{*}$ \\
\hline Pedro de Abadia & 2 & $200 \mathrm{r} . /$ von. & $8 / 4 / 64$ \\
Pedro Liber & 1 & - & $7 / 4 / 64$ \\
Juan de Coper & 2 & $900 \mathrm{r} . /$ von. & $1 / 6 / 65$ \\
Pedro Molet & 1 & $15 \mathrm{r} . /$ plata mes & $30 / 8 / 59$ \\
Juan de Paris & 2 & 20 doblones año & $24 / 9 / 64$ \\
Juan Permaza & 1 & $1.050 \mathrm{r} . /$ von. & $14 / 7 / 65$ \\
Juan Petit & - & - & $2 / 9 / 63$ \\
Juan Descot & - & - & - \\
Antonio Pons & 1 & 21 doblones & $11 / 9 / 63$ \\
Juan Labiña & 2 & 280 libras & \\
Juan de Sanmartin & 14 meses & $100 \mathrm{r} . /$ a ocho & \\
Juan Dupón & 1 & 150 libras & $13 / 12 / 62$ \\
\hline
\end{tabular}

* Elaboración propia.

CUADRO III

\begin{tabular}{|c|c|c|}
\hline \multicolumn{3}{|c|}{ VENDEDORES DE PEINES CALLEJEROS* } \\
\hline Vendedores & Período (años) & Salario \\
\hline Juan de Bruna & 1 & $500 \mathrm{r} . / \mathrm{von}$. \\
\hline Juan de Bordanava & 1 & $300 \mathrm{r} . / \mathrm{von}$. \\
\hline Juan de Blas & 1 & $400 \mathrm{r} / \mathrm{von}$ \\
\hline Juan Nolay & 1 & $400 \mathrm{r} / \mathrm{ivon}$ \\
\hline Juan de Abadia & 1 & $500 \mathrm{r} . / \mathrm{von}$. \\
\hline Juan de la Rosa & - & $22 \mathrm{r}$. plata a ocho \\
\hline Francisco Gascón & $1 / 2$ & $230 \mathrm{r} . / \mathrm{von}$ \\
\hline Pedro Nabasiera & 1 & 400 r./von. \\
\hline Miguel Facolaut & 5 & 7.829 r./von. (a comision) \\
\hline Antonio Berdier & 1 & 500 r./von \\
\hline
\end{tabular}

* Elaboración propia.

La producción que se vendía en las tiendas y lonjas de los mercaderes peineros no siempre procedía de su obrador. La demanda de la Corte exigía afrontarla fuera de la estricta reglamentación gremial que limitaba la producción del artesano. El contrato por «encargo", también denominado 
Verlargsystem ${ }^{41}$, resolvía el problema ya que proporcionaba a los talleres artesanales una producción adicional para cubrir la demanda de centros urbanos como Madrid, convirtiendo al modesto maestro-peinero en un simple "asalariado» del capitalista que le contrataba (Cuadro IV). En estos documentos se estipula la producción en cantidad, calidad y precio, incluyendo también cláusulas de exclusividad. Son las condiciones recogidas en el contrato firmado el 29 de septiembre de 1662 entre la compañia de Jacques Pineo y Juan Tisne, maestros peineros residentes en Madrid, y Guillermo La Alfeche de Loysan, "mercader de hacer peines", quien se compromete a fabricar una determinada cantidad de peines que enviará desde Burdeos a la Corte a lo largo del año, lo cual, por otra parte, viene a demostrar que la intervención y el control de la producción por parte del capital mercantil no era algo ocasional, siendo uno de los pasos previos para la participación del artesanado madrileño en el naciente capitalismo madrileño, en este caso, en el ámbito de la producción.

La comercialización de peines y sus derivados comprendía la venta al por mayor en "lonja abierta", como ya hemos dicho - recordemos que el sistema de "lonja cerrada" era básicamente venta en almacén por "frangotes, fardos cajas en paques y barriles, tal y como se saca de la aduana" ${ }^{42}$. El Verlargsystem se convierte así en el método de abastecimiento de estas lonjas que, dirigidas por hombres del comercio que trafican con una gama más amplia de mercancias, necesitan una producción importante de peines con que abastecer a su clientela madrileña. En algunas ocasiones estas compras las realizaban los empleados del taller-

Recordemos que el verlargsystem se ve favorecido por la débil estructura gremial existente en los núcleos urbanos castellanos, especialmente en la Corte madrileña: GonzAl F. ENCISO. A., "La protoindustrialización en España", Revista de Historia Económica. II, 1. (1984), págs. 15 y 16 ; Cariandf. R. Carlos $V$ y sus banqueros, vol. 1, pág. 17. A través de este sistema se establecieron ya desde la Baja Edad Media en Castilla, en el ámbito de la empresa textil, unas relaciones contractuales entre el "asalariado" y los mercaderes capitalistas por las que los primeros ponian su tiempo de trabajo excedentario y los segundos se encargaban de distribuir el producto y comercializarlo en un mercado amplio y lejano. Ver CASADO. Hilario, Señores. mercaderes y campesinos. La comarca de Burgos a fines de la Edad Media. Valladolid, 1987, pág. 243. En el ámbito gremial madrileño se repiten estas prácticas a las que nuestras fuentes notariales hacen referencia, como lo ha demostrado a su vez LOF' 7 CASIAN. A. Los gremios artisticos de Madrid en el siglo xwil y primer tercio del siglo xix: Los oficios de la madera, textil y piel, Madrid Tesis U.A.M. (microfichas) Madrid. 1991. pág. 11. Asi, el sistema de "encargo", a través del cual el comerciante capitalista anticipa el capital necesario para la fabricación del producto, se extiende como práctica habitual en el panorama industrial de la Corte

AHN, Universidades, Libro 1181 "Papeles relativos a Madrid", fol. 187: "Los Cinco Gremios de Madrid pusieron en la secretaria de la Real Junta de Comercio a pedimento del fiscal y por decreto de ella en marzo de 1740 los documentos siguientes...". Agradezco a Valentín Moreno Gállego la localización de este libro manuscrito 
tienda por delegación del maestro o administrador de la compañia. Junto a este tipo de comercialización de la línea de productos que se fabricaban en Madrid, aparecia la venta al menudeo o vareado, es decir, por docenas y unidades.

\section{CUADRO IV}

\begin{tabular}{|c|c|c|c|c|c|}
\hline \multicolumn{6}{|c|}{ ABASTECIMIENTO DE LAS CASAS TIENDAS DE PEINEROS* } \\
\hline $\begin{array}{l}\text { Casa taller } \\
\text { (Capitalista) }\end{array}$ & Contrato & $\begin{array}{l}\text { Proveedor } \\
\text { (Asalariado) }\end{array}$ & Localidad & Mercancias & Precios \\
\hline $\begin{array}{l}\text { J. Pineo y } \\
\text { R. Favre }\end{array}$ & $\begin{array}{c}10 / 7 / 62 \\
\text { hasta } 1662 \\
\text { hasta } 1664\end{array}$ & $\begin{array}{l}\text { G. Cordurie } \\
\text { B. Pineo } \\
\text { B. Pineo }\end{array}$ & $\begin{array}{l}\text { Bierzo } \\
\text { Huesca } \\
\text { Huesca }\end{array}$ & $\begin{array}{l}\text { Peines y otros. } \\
\text { Dependencia de peines. } \\
\text { Fabricación de peines } \\
\text { durante un año }\end{array}$ & $\begin{array}{l}980 \mathrm{r} . / \text { von. } \\
210 \mathrm{r} . / \mathrm{von} \\
49 \text { y } 35 \mathrm{r} / \\
\text { plata (1) }\end{array}$ \\
\hline P. Mercadet & $6 / 11 / 64$ & J. Arçisete & Zaragoza & $\begin{array}{l}\text { Peines de Box (2) } \\
\text { (cuatro tipos) }\end{array}$ & $\begin{array}{c}26,36.57 \text { y } \\
65 \mathrm{r} / \mathrm{plata}\end{array}$ \\
\hline $\begin{array}{l}\text { Cía Mercadet } \\
\text { y Tapia } \\
\text { D. Vegue y }\end{array}$ & $9 / 11 / 63$ & $\begin{array}{l}\text { J. Cosat y } \\
\text { Bibier }\end{array}$ & Barbastro & $\begin{array}{l}\text { Peines de Box (4) } \\
\text { (dos tipos) }\end{array}$ & $\begin{array}{l}29 \text { y } 43 \\
\text { r.plata }\end{array}$ \\
\hline B. Correa & $9 / 5 / 62$ & J. Dagas & Calatayud & Peines & $1.550 \mathrm{r} / \mathrm{van}(3)$ \\
\hline $\begin{array}{c}\text { Cía. Tisne } \\
\text { y Pineo }\end{array}$ & $29 / 9 / 62$ & J. Laguardia (5) & Pamplona & Peines & $\begin{array}{c}\text { (desconocemos } \\
\text { dato) }\end{array}$ \\
\hline $\begin{array}{c}\text { Cía Tisne } \\
\text { y Pineo }\end{array}$ & & $\begin{array}{l}\text { G. Alfeche } \\
\text { De Laysan }\end{array}$ & Burdeos & Peines por un año & idem. \\
\hline
\end{tabular}

* Elaboración propia.

(1) En el modelo "meiçiana" el precio se estipula en 49 reales de plata por cada cien peines. El modelo "gorna" a 35 reales de plata por cada cien. El destino es Madrid, vía Zaragoza.

(2) Del mismo modo, el precio varía según calidades.

(3) AHPM, P० 7250, fols. 174-174v., 9 de mayo de 1662.

(4) Según calidades: 43 reales de plata el ciento de "a ciento y veinte y un peines cada ciento" 29 reales de plata el ciento "de a ciento y veinte y un peines cada ciento".

(5) Juan de la Guardia, maestro peinero, es un intermediario que compra a otros maestros artesanos asalalriados (Ramón de Elías, Juan de Álava y Diego Jirao) las cantidades al por mayor de peines que traslada a la Corte.

\section{ACTIVIDAD ECONÓMICA DE LOS ESCRITORIOS DE LOS FABRICANTES PEINEROS}

El ejercicio de la actividad comercial en el seno de la economía madrileña conduce a nuestros artesanos a enfrentarse a la demanda de la Corte dentro de las rígidas limitaciones de las ordenanzas gremiales, esto es, 
una producción y comercialización limitadas. Esta situación les llevaría a tener que salvar una serie de barreras. En efecto, en las páginas anteriores hablábamos del sistema de "encargo" como producción adicional que llegaba al taller del maestro capitalista. Con este procedimiento se salvaban los impedimientos gremiales y la comercialización se ajustaba a las rigidas estructuras gremiales.

La coyuntura económica madrileña desfavorable de mediados de siglo, unida a la lógica expansión comercial tras la libertad de comercio con Francia a raíz de la firma del Tratado de los Pirineos (1659), colocaban a la colonia francesa y a todo aquel que estaba interesado en el comercio con el país vecino en una posición preferente. Sin embargo, el análisis de las fuentes notariales nos descubre una constante en los negocios de estos agentes económicos: la falta de liquidez del pequeño comercio en el ámbito de la demanda suntuaria que tiene Madrid, causado no por una caida de la actividad mercantil, sino por los impagos de los morosos -hay numerosos pleitos que lo confirman-, lo que provocaba el traspaso de escrituras de obligación ante la insolvencia de los comerciantes que las firmaban. La coyuntura sería más favorable para los artesanos comerciantes que se habian introducido en las redes del comercio al por mayor, ya que la Corte les proporcionaba las vías para un cierto enriquecimiento económico.

Los peines que llegaban a Madrid como mercancías importadas procedian tradicionalmente de los mercados franceses ${ }^{43}$. Eran fuertemente demandados a causa del desmedido afán de lujo popularizado en aquella sociedad ${ }^{44}$,que convertía el consumo de estos productos en una actividad lucrativa. Los negocios y tratos de los mercaderes peineros especializados en la comercialización de peines se reactivaban con inyecciones de capital procedentes de una acumulación primitiva de capital comercial o de préstamos del círculo mercantil al que pertenecian, cuando no de la conjunción de ambos. Así participan en el desarrollo del comercio madrileño, siendo financiados, en principio, por los prestamistas de su círculo mercantil originario (carreteros de Zaragoza), luego, ya en Madrid, por la élite urbana madrileña, que también financia al resto de peineros vecinos de la Corte. Son los prestamistas castellanos, como Lorenzo de Santisteban,

'BNM, Manuscritos (Mss.) 18.722-7, fol. 16, «Relación de mercancias que vienen de Francia" (sin fecha). Un ejemplo de la popularidad de estos productos: SANCHEZ BELEN, J.A. y Ramos Medina, M.D., op. cit. págs. 310-314. Cuadro II: "Nómina de mercaderes de Málaga a quienes se han embargado géneros de Francia".

14 CAPELla, M. y MATILLA TASCON, A., Los Cinco gremios mayores de Madrid. Estudio histórico critico. Madrid, 1957, pág. 11. 
Cristóbal Estopani, o Isabel Catalina de Contreras Martínez del Pino, quienes otorgan en varias ocasiones préstamos a corto plazo y en concepto de "hacer bien y buena obra" a Juan Corral, Juan Tisne o Jacques Pineo, artesanos mercaderes.

Los instrumentos empleados en la comercialización (escrituras de obligación y letras de cambio) sirven al hombre de negocios de trampolín para introducirse en los mecanismos financieros de mayor consideración, como en la representación de intereses ajenos en cobros a comisión ${ }^{45} \mathrm{O}$ en asuntos en los que participan como depositarios de dinero procedentes de otros maestros y oficiales del gremio ${ }^{46}$, o como prestamistas en concepto de préstamo-obligación, esto es, crédito a corto plazo para financiar la compra de mercancias, facilitando así la comercialización de un producto en manos de una clientela con falta de liquidez, y préstamos de dinero "17. Este es el caso, por ejemplo, de Juan Vallejo ${ }^{48}$, depositario de tres partidas de dinero que dejó su primo Juan Bautista Vallejo (once doblones en 1676, tres doblones en 29 de septiembre de 1677 y ocho doblones el año 1677), para que por delegación suya y en su nombre pague diecinueve doblones a Antonio de Gorbas, testamentario de Juan Rustalet, francés de la villa del Tiemblo (Ávila) al que le debe dicha cantidad. Este fenómeno se repite cuando Domingo Vegue, maestro peinero residente en Madrid, actúa en 1663 como depositario bancario de Francisco Hernand, oficial peinero. También el uso de letras de cambio entre los peineros con claros intereses mercantiles en el gran comercio se convierte en un instrumento de pago frecuente. Juan del Plá, oficial peinero, recibe de Manuel Serrano Montero, mercader de lonja y vecino de la villa, 1.746 reales de vellón de una letra dada a su favor por Cristóbal de Parra, vecino de Jaén a ocho dias vistas ${ }^{19}$. Por todo ello, las actividades referidas les situaban en la línea de los gremios del comercio, más que de la industria ${ }^{50}$.

Por otra parte, las empresas comerciales eran inyectadas con capital procedente de los beneficios obtenidos con la comercialización de los pro-

AHPM, Prot. 10.108, 23 de agosto de 1683 ( $\sin$ foliar).

AHPM, Prot 9776, fols. 55-56v. el 12 de abril de 1679 y Prot. 7251, fol. 112. Domingo Vegue, maestro peinero depositario de dinero procedentes de ahorro doméstico de Francisco Hernán, maestro peinero, en concepto de depósito y por una cantidad que tiene en concepto de venta de mercancias que le debe Bernardo Carroge. estos papeles se los traspasa a Pedro Mercadet al que pagó con ellos una deuda que debe a este último. utilizando estos documentos notariales como papel moneda

AHPM. Prot 9159, fols. 226-226v: Prot. 7251, fois. 126-126v y Prot. 9772 fols. $11-12 v$.

AHPM, Prot 9776 , fols $55-56 \mathrm{v}$

AHPM. Prot 9775, 5 de abril de de 1678, fols. 51-52v.

Captia. M. y Matilia Tascon, A: Op. cit. pags, 42-43. 
ductos artesanales. Los agremiados madrileños con mayor potencial económico comerciaron no sólo en plazas mercantiles nacionales, como sucedía con los de Valencia, Navarra y Aragón, sino que también realizaban transacciones hacia plazas francesas, como París, Burdeos, Bayona o en las zonas de Béarn, y Languedoc. Muchas de estas actividades se desarrollaban a través de compañías, en las que figuraban los maestros agremiados como compañeros en un mismo negocio. La actividad mercantil y financiera empezaba a separarse del círculo estrictamente gremial para pasar al del capitalismo comercial ${ }^{51}$.

\section{LAS REDES MERCANTILES Y FINANCIERAS}

Las empresas peineras con sede en Madrid disponian de un sistema de información sustentado en un pilar básico fuera de la plaza madrileña: la correspondencia que recibian de los corresponsales repartidos en diferentes núcleos mercantiles nacionales y extranjeros. Basta asomarse a la documentación privada, especialmente a los poderes notariales pues la correspondencia mercantil no ha llegado hasta nosotros, para comprobar cómo los corresponsales de estas empresas enviaban a la Corte mercancias y dinero que proporcionaban al negocio de estos mercaderes fabricantes pingües beneficios procedentes, por una parte, del mercado aragonés y navarro, y, por otra, del mercado francés. Además se dibujaba un interesante mercado financiero que por el momento sólo vamos a esbozar en las siguientes páginas.

La geografia del mercado de los escritorios de fabricante "peineros" con tienda abierta en la Corte se articula entre las diferentes zonas productoras de Aragón, Navarra y sur de Francia (Burdeos, Béarn, Languedoc) que les abastecen del producto y aquellas otras hacia las que lo distribuyen, particularmente los núcleos urbanos castellanos y andaluces del interior peninsular, pues no debe olvidarse que Madrid es un importante centro redistribuidor de mercancias procedentes de otros mercados nacionales y extranjeros. Todo este flujo comercial, y en menor medida financiero, estaba presidido, además, por unas sólidas relaciones de parentesco y lazos nacionales que sustentaban las redes mercantiles y financieras de los mercaderes fabricantes madrileños, creando unas sólidas estrategias empresariales deudoras, en buena parte, del éxito o del fracaso de estas empresas.

Molas Ribalta, P., Los gremios barceloneses..., op. cit., pág. 205. 
Zaragoza, núcleo comercial y productor de primer orden en el reino de Aragón, que contaba con la presencia de una notable colonia gala entre sus artesanos y mercaderes, constituye el centro neurálgico de donde se va a nutrir gran parte de la comunidad de fabricantes peineros en Madrid ${ }^{52}$, pues la fuerte recesión demográfica y económica en la que se vió envuelta la ciudad a mediados del siglo XVII, y que afectó profundamente a las actividades industriales, especialmente la textil ${ }^{53}$, junto al atractivo mercado que ofrecía la Corte y las posibilidades de beneficios para sus empresas, fueron factores decisivos, sin duda, del traslado a Madrid de algunos artesanos peineros de origen francés ${ }^{54}$, fenómeno que se observa también por estas fechas en relación con los artesanos de otros lugares fronterizos como Pamplona, Huesca o Barbastro, quienes, tras haber residido un cierto tiempo, llegando en ocasiones a avecindarse allí, se trasladan a Madrid en calidad de oficiales artesanos ${ }^{55}$, aun cuando mantenga escritorios de comercio o, en el peor de los casos, simplemente contactos con sus lugares de origen por medio de factores y corresponsales amigos o familiares del mercader fabricante, que continuan representando sus intereses en aquel núcleo urbano.

\footnotetext{
BNM, Varios Especiales, 28-42 «Memoriales de los mercaderes naturales de este reino de Aragón". Garcia Mercadal, J., Viaje por España. Madrid, 1972, pág. 130 donde nos recuerda: "fui sorprendido hasta el último extremo al hallar alli que todo el mundo hablaba frances en las calles", Juan Fco. Pablo de Gondi, cardenal de Retz. SaLAS AuSENS, J. A., "La inmigración francesa en Aragón en la época moderna. Estudios del Departamento de Historia Moderna. Zaragoza, (198586), págs. 72-73; REDONDO VEINTEMILLAS, G., "Las relaciones comerciales aragonesa-francesa en la Edad Moderna". Estudios del Departamento de Historia Moderna, Zaragoza (1985-86), págs. 131-132. "Datos para el estudio del comercio con Francia en 1675". Estudios del Departamento de Historia Moderna. Zaragoza (1976), págs. 213-237. VV.AA. La monarquia hispánica en crisis, Centre d'Estudis d'História Moderna «Pierre Vilar». Barcelona, 1992, pág. 51. Uno de los miedos de la Corte en la coyuntura critica de los años cuarenta del siglo XVII fue la posibilidad de que Aragón y Valencia se sumaran a la rebelión, especialmente por varios factores: el curso de los acontecimientos que estaba adquiriendo la revuelta catalana, la multiplicación de noticias sobre intentos de espionaje $y$, especialmente, la existencia de una importante colonia de mercaderes franceses en Zaragoza y otras poblaciones: al respecto ver, $M^{a}$ C. ANSÓN CALvo, "Zaragoza como lugar de inmigración en el siglo XVil», La ciudad de Zaragoza en la Corona de Aragón. Zaragoza, $X$ Congreso de $H^{a}$ de la Corona de Aragón, 1984, pág. 27, tabla 1, donde se recoge la presencia de franceses en la parroquia de San Pablo y págs. 30-31.

5 Colas latorre, G. y Salas Ausens, J.A., Aragón bajo los Austrias. Zaragoza, 1977, págs. 91, y 93-94; REDONDO VEINTEMILLAS, G., Las corporaciones de artesanos de Zaragoza en el siglo xvi. Zaragoza, 1982; MAISO GONZALEZ, J., "La coyuntura económica de Aragón a mitad del siglo xVII y el motín contra los valones", Cuadernos de Investigación. Logroño, 1975, págs. 94-104

s. Zaragoza era un punto de apoyo esencial en el camino hacia Madrid, permaneciendo este flujo a principios del siglo Xvili. Ver Perrez Saraion, G. op. cit., pág. 236.

:L Los extranjeros en ciudades como Barbastro eran población de paso hacia otros centros urbanos de la Península, aun cuando muchos de ellos habian contraido matrimonio con naturales del reino: SalAs AUSENS, J.A., La población de Barbastro en el siglo xVil y xvill, op. cit., págs. 232 y 242.
} 
Conocemos varios casos, como el de Juan de Tapia, de origen francés y vecino de Zaragoza, que asume las funciones de administrador-corresponsal de los negocios de Juan Cordurie en su ciudad. Los lazos que unian a estos hombres eran intensos y el papel de ciudad productora de mercancias del ramo se observa en sus relaciones con los transportistas de éstas como Juan Brun, carretero de Zaragoza, y Juan Arçisete, maestro mercader, que se convirtió en proveedor de peines de la casa-tienda Cordurie en Madrid. Asimismo Hernando Cordurie es corresponsal de su hermano Juan en negocios de cobros, en concepto de comisión, a Hernando de Tapia, peinero y mercader de lonja, en Zaragoza, el 5 de abril de 1661. Este asunto parece que no queda concluido a la muerte de Juan Cordurie siendo su viuda, Raimunda Favre, y Jacques Pineo los que el 12 de enero de 1662 den poder a los procuradores Nicolás Tornero y Francisco Sierra para que sigan el pleito contra Hernando de Tapia, «el mayor", por 220 reales que adeuda por la compra de 10 mazos de "granates de açabache ${ }^{56}$ '.

En el párrafo anterior aludíamos al movimiento migratorio protagonizado por algunos artesanos desde Huesca, región que abasteció de peines a los talleres-tienda madrileños. La tradición artesanal de esta zona venía ya de antiguo y estaba firmemente arraigada por la buena calidad de los productos fabricados, especialmente, por artesanos franceses. Ricardo del $\mathrm{Arco}^{57}$, coincidía hace ya tiempo en que Huesca en esa centuria fue una cludad que tuvo una importante actividad artesanal y que la producción comercializada se dirigía en gran parte a la Corte vía Zaragoza ${ }^{58}$. Sin embargo éstos no eran los únicos centros que abastecian a Madrid, pues núcleos urbanos como Barbastro ${ }^{59} \mathrm{y}$ Calatayud también aparecen registrados en las fuentes consultadas como centros abastecedores de los escritorios de fabricante madrileños.

AHPM, Prot. 7250, tols. 9-9v

Ricafido del. Arco, Apuntes sobre el antiguo régimen municipal de Huesca. Huesca, 1910, págs. 107 y ss.; Antiguos Gremios de Huesca, Estudio preliminar p. XVIl". Huesca, 1912. Francisco Codera. Informe: "Antiguos gremios de Huesca". Boletin de la Real Academia de Historia, tomo LX, Cuaderno III, marzo, 1912, págs. 229-232. (Recensión del contenido del libro de Ricardo del Arco del mismo titulo);

Ignacio de Asso: Historia de la Economia politica de Aragón. Zaragoza, 1983, (ed. facsímil). págs. 125-126

AHPM, Prot. 7.251, fol. 469-470v “Escritura de encargo entre Hernando de Tapia y Pedro Mercadet, mercaderes peineros y Juan Cosat y Juan Bibier, maestros peineros y vecinos de la ciudad de Barbastro, el 9 de septiembre de 1663". Sobre este núcleo urbano y su comunidad francesa ver: SALA AUSENS, J.A., "La inmigración francesa a Barbastro en los siglos XVI y XVI»", Estudios. Zaragoza, 1977, págs. 58 y 59, cuadro 6\%, donde nos facilita la cifra de 11 peineros y 12 mercaderes de origen francés. Con mayor profundidad analiza este centro urbano oscense en su tesis: La población de Barbastro en los siglos xvi y xvil. Zaragoza, 1981, págs. 215-322 
Del mismo modo, desde Navarra se había trazado otra red mercantil en contacto con la Corte. Domingo Vallejo, mercader peinero avecindado en Madrid, delega poderes el 29 de abril de 1661 en Juan de la Guardia, vecino de Pamplona para que compre en su nombre en la capital navarra peines, flautas, silbatos y otras cosas para el abastecimiento de su tienda sita en la calle Mayor de Madrid ${ }^{60}$. Asimismo, el 18 de junio de 1660 ordena a Juar de Casanova cobrar una suma de dinero a Guillermo Melat, vecino de la ciudad de Pamplona, posiblemente en concepto de préstamo de dinero. Finalmente, también tenemos noticias de que Domingo Vallejo otorga poderes a Juan Cordurie ${ }^{61}$, otro de los maestros mercaderes afincados en Navarra y que se trasladaria a la Corte poco tiempo después (Cuadro V). Todos estos ejemplos permiten sospechar que estas redes mercantiles sustentaban flujos crediticios de importancia, aunque por el momento sólo podemos ofrecer breves pinceladas.

La ciudad de Valencia, a pesar de la crisis manufacturera de los cincuenta, de la que se recuperaría en el reinado de Carlos II, era una plaza mercantil de cierta importancia para las empresas artesanas que estamos analizando ya que contaba con una colonia mercantil francesa importante ${ }^{62}$, aun cuando las constantes crisis bélicas del período colocasen a este colectivo en una situación crítica ${ }^{63}$. El foco valenciano nos sitúa, así, en otra de las vías periféricas de acceso, no sólo de movimientos migratorios procedentes del sur de Francia ${ }^{64}$, sino también de intercambios comerciales de gran importancia, ya que sería utilizada para introducir productos franceses en el levante mediterráneo español conducidos a través de Toulouse, Carcasonne, Narbona, Perpiñan y Barcelona hasta llegar a Valencia desde donde se redistribuian. Desgraciadamente, no contamos por el momento con suficientes datos sobre corresponsales, mercancias y clientes. Mercaderes como Pedro

(0) AHPM, Prot. 7249 , fol. 670 .

.1 AHPM, Prot. 7249, fol. 605; Prot. 7248 fols. 335-335v y Prot. 7250 , fols. 506 y $506 \mathrm{v}$. Sabemos que las conexiones de estos maestros-mercaderes con Navarra se encuentran sólidamente arraigadas a las redes familiares que mantienen en la Comunidad foral, ya que algunos de ellos, -. es el caso de Juan Vallejo y Hernando de Tapia- son oriundos de la Baja Navarra.

Molas Ribalta, P., La burguesia mercantil.., op.cit., pág. 210.

63 PoItrineau, A : "La inmigración francesa en el reino de Valencia (siglos XVI-Xix)", Moneda y Crédito, 137 (1976), págs. 103-133 y 111.

AHPM, Prot. 9767, 28 enero de 1970. Juan Descot, oficial peinero que residió en casa de Juan Calot, maestro peinero con tienda abierta en la Puerta del Sol de Madrid. Originario del reino de Francia, reside en Madrid en ese momento, aunque con fuertes contactos con la colonia francesa valenciana, ya que tiene concedido un préstamo obligación de Antonio Recarte, maestro peinero francés residente en Valencia en concepto de alimentos y por una fianza de un total de 26 reales de a ocho de plata. 


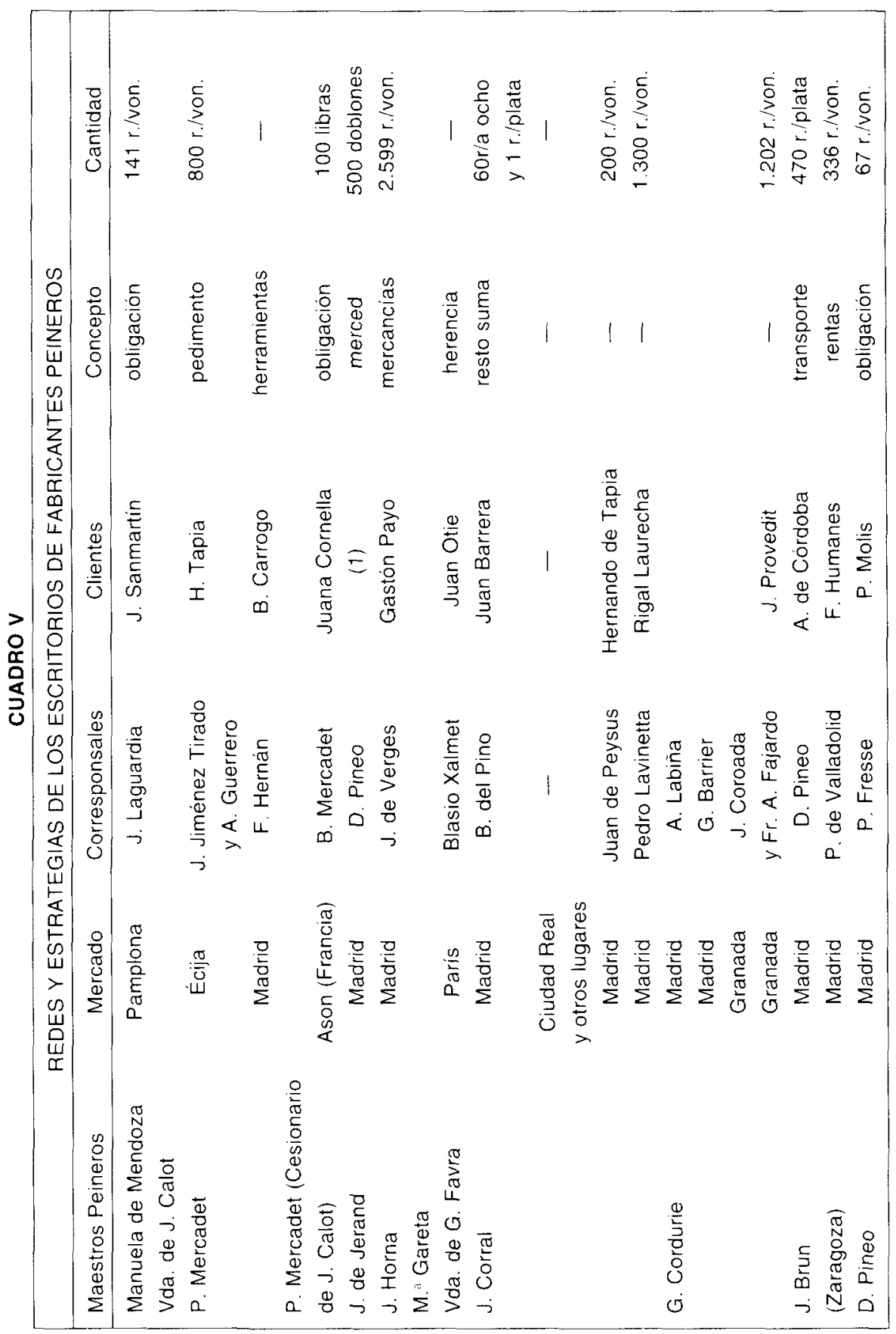


Casanova, corresponsal valenciano de uno de nuestros mercaderes peineros avecindado en Madrid, y que tenía, entre otros, el encargo de cobrar ciertas cantidades adeudas por Pedro Laberia, fueron quienes contactaron durante los años sesenta del siglo XVII con peineros del reino de Valencia. Lo mismo sucedería con Juan Nolay, que adeuda 158 reales de vellón, y con Juan Forcan ${ }^{65}$.

Como empresas de servicios mercantiles y financieros su más importante centro de recepción de prestaciones lo constituyó la propia Corte, cuyos habitantes demandaban un gran número de actividades financieromercantiles que estaban fielmente representadas en los escritorios de los mercaderes peineros. Así, Pablo Baco, maestro peinero de origen francés, representaba los intereses de Juan Cordurie el 14 de enero de 1659 en el cobro de ciertas sumas de dinero a terceros, en concreto a clientes de la Casa Cordurie, como Juan Gutiérrez, panadero de Madrid que vivía en Lavapiés, como "principal», y Juan Turena como su "fiador». Del mismo modo, al ser centro redistribuidor de mercancias hacia el mercado interior castellano (cuadro $\mathrm{V}$ ), la plaza madrileña contó con mercaderes cuya actividad cubría dicha demanda. Este era el caso de la compañía Corral y Davadia, que mantiene tratos mercantiles en Ciudad Real, según se desprende del poder dado el 16 de agosto de 1660 al mercader Pascual del Campo para que cobrara en esta ciudad y en otros lugares de la región varias cantidades de dinero que le adeudaban. Sin embargo, la mayoría de los artesanos-peineros madrileños desarrollaron su actividad económica en la Villa y Corte, requiriendo los servicios de un gran número de apoderados y factores para que se encargaran de cobrar a sus clientes. Estos eran los casos de Juan Peysus, a quien J. Corral y Cia otorgó poder el 4 de agosto de 1661 para exigir a Hernando de Tapia, mercader peinero, el pago de lo que debia satisfacer por determinadas mercancias, - el de Bernardo del Pino quien también recibe autorización de J. Corral y Cia por medio de un poder fechado el 24 de marzo de 1663 para cobrar de Juan Barrera, oficial de hacer peines, lo que adeudaba en concepto de resto de mayor cuenta y un préstamo de 60 reales de plata de a ocho (ver Cuadro V).

Fuera de estas redes estables se creaban otras de carácter más esporádico constituidas por comerciantes ambulantes de origen francés, los que las fuentes denominan mercaderes "cajeros", que venden por las calles de Madrid o en las ciudades y pueblos del hinterland regional madri-

AHPM, Prot. 9771 , fols. $146-147 \mathrm{~V}$ 
leño los productos procedentes de los escritorios del fabricante peinero. Pedro Labinetta, como corresponsal de uno de estos fabricantes madrileños, tenía el encargo de cobrar a Rigal Laurecha, "cajero" francés, una cantidad que adeudaba en concepto de escritura renovada el 19 de agosto de 1662 de otra firmada el 14 de agosto de 1656, lo que, por otra parte, vuelve a recordarnos la falta de liquidez del pequeño comercio.

De este modo el radio de acción de los negocios de estos mercaderes se extendía por toda la Península entrando en relación con las diferentes colonias de franceses en este ramo de la producción e incluso representando intereses franceses en nuestro pais, como sucede cuando Domingo Vallejo, el 19 de agosto de 1673, recibe poder de Juan de Escot, avecindado en Francia y residente en Madrid, para que cobre de Andrés Verges, oriundo de la misma zona geográfica que Juan de Escot y que se encontraba en Francia ${ }^{66}$, la cantidad estipulada por contrato. En Andalucia esta vez, Pedro Mercadet otorga poder para cobrar a Juan Jiménez, vecino de Écija, en 1667. También Juan Horna, maestro peinero vecino de Toledo y con tienda abierta en Madrid, daba poder el 23 de abril de 1666 a Juan de Verges, mercader sevillano, para que en su nombre perciba del mercader francés Gastón Payo la cantidad de 2.599 reales y medio de vellón en concepto de mercancías vendidas el 27 de julio de 1665.

Fuera de la península, las conexiones de este grupo mercantil con otros afincados en plazas de la categoría de Paris ${ }^{67}$, Burdeos o Bayona, llegando hasta Béarn-Languedoc, zonas de donde procedian nuestros artesanos-mercaderes, estaban sustentadas en una red familiar que resguardaba sus intereses económicos, sin olvidar que como zonas de producción artesanal francesa de importancia ejercieron un papel preponderante.

\section{CONCLUSIONES}

Aunque lo expuesto hasta ahora no agota el tema sino que, bien al contrario, abre el camino a nuevas investigaciones sobre los gremios desde la perspectiva del análisis microeconómico de sus empresas y la funcionalidad de sus redes mercantiles y financieras, algunas conclusiones

AHPM. Prot. 10.104. fols. 290-290v.. 19 de agosto de 1673.

SArtos. F. El no importa de Espana. Madrid, 1667, BNM. R-31678, fol 144, donde esta fuente literaria localiza un escritorio de comercio de un mercader francés que labra peines en su tienda y que tiene abiertas en Madrid dos tiendas de peines y una lonja de mercancias francesas y donde su hijo ostenta el cargo de administrador de las mismas 
cabe destacar. En primer lugar, participando como sujetos activos en la incipiente economía capitalista, los mercaderes fabricantes de peines contribuyen en el seno del gremialismo madrileño a la reactivación comercial de Madrid, siendo un factor clave en la capitalización de algunos talleres artesanales en Aragón y otros centros periféricos asi como en la permanencia de estos circuitos en el comercio de la Corte. En segundo término, creemos también que la evolución del mercader fabricante peinero bien puede ser uno de los gérmenes de la posterior agrupación de los agremiados madrileños, por una parte, en gremios artesanales "menores" $y$, por otra, en gremios de carácter comercial, los futuros Cinco Gremios Mayores de Madrid. Con todo, sus empresas, impregnadas de un fuerte mimetismo y versatilidad, les permitian actuar con mayor libertad dentro de los límites establecidos entre gremialismo y capitalismo. 
APÉNDICE I

ÁRBOLES GENEALÓGICOS

\section{CASA CORDURIE-PINEO}

CASA CORDURIE

Guillermo CORDURIE

Languedoc

Catalina JOBEN

Hernando FAVRE

Languedoc

Catalina BONEL

$$
\begin{gathered}
\text { Juan CORDURIE } \\
\text { V Madrid } \\
(\dagger 1662)
\end{gathered}
$$

RAIMUNDA FAVRE

$V^{\prime \prime}$ Madrid

Maria CORDURIE

$(† 1661)$

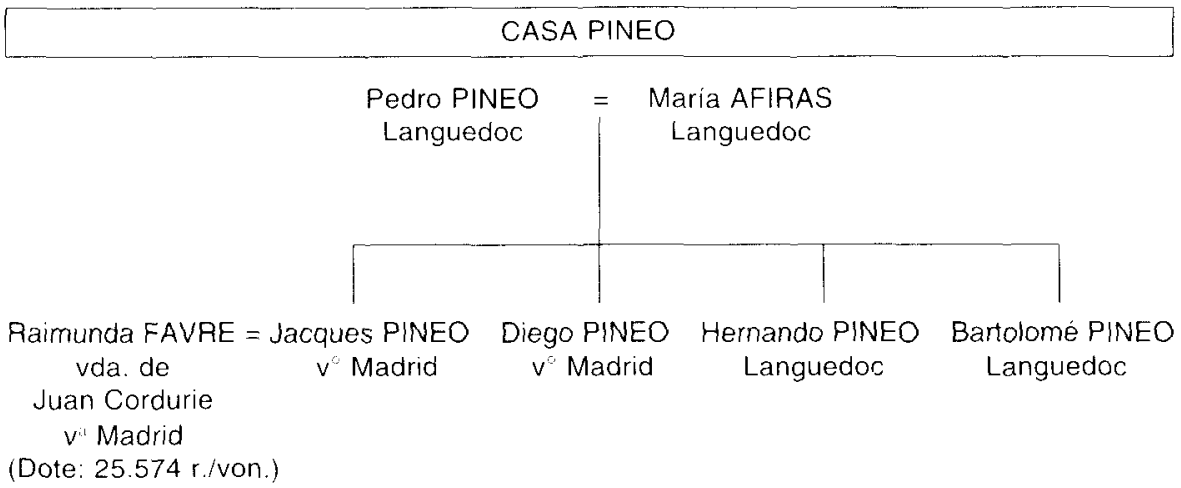

$(+)$ : difuntos

$(=)$ : matrimonios

Fuf NTE: AHPM. Prot. 7249 , fols, $450-52 \mathrm{v}$ y fols $610-114 \mathrm{v}$ 
APÉNDICE II

\begin{tabular}{|c|c|c|}
\hline $\begin{array}{c}\text { MAESTROS-MERCADERES } \\
\text { PEINEROS }\end{array}$ & $\begin{array}{l}\text { OFICIAL } \\
\text { PEINERO }\end{array}$ & $\begin{array}{l}\text { VENDEDOR DE } \\
\text { PEINES }\end{array}$ \\
\hline Juan Vallejo & - & Juan Bonete \\
\hline \multirow[t]{2}{*}{ Bdo de la Peña } & Juan de Coper & - \\
\hline & Pedro de Abadía & - \\
\hline Juan Peysus & - & Juan de Bruna \\
\hline Juan del Corral & Pedro Molet & - \\
\hline Guillermo Cordurie & - & Juan de Blas \\
\hline \multirow[t]{6}{*}{ Juan Tisne } & - & Juan Nolay \\
\hline & & Pedro Abadia \\
\hline & & Pedro Fillot \\
\hline & & Juan La Rosa \\
\hline & Juan de París & - \\
\hline & Juan Permaza & - \\
\hline Guillermo Cordurie & - & Fco. Gascón \\
\hline Juan Arcisete & Juan Petit & P Nabasiera \\
\hline Juan Calot & Juan Descot & - \\
\hline \multirow[t]{2}{*}{ Diego Pineo } & - & Andrés Berdier \\
\hline & & Miguel Falcoult \\
\hline \multirow[t]{2}{*}{ Jacques Pineo } & Antonio Pons & - \\
\hline & Juan Fure & - \\
\hline \multirow[t]{2}{*}{ Guillermo Rossao } & Bernardo & - \\
\hline & Audismadigou & - \\
\hline Bartolomé de Abadía & Tristan de Cali & - \\
\hline Hernando de Tapia y & Juan Dupón & - \\
\hline \multirow[t]{2}{*}{ Bernardo Peberán } & Juan de San Martin & - \\
\hline & Juan de Labiña & - \\
\hline
\end{tabular}

* Elaboración propia. 